\title{
Potentially dangerous sleeping environments and accidental asphyxia in infancy and early childhood
}

\author{
Roger W Byard, Susan Beal, Anthony J Bourne
}

Departments of Histopathology and Ambulatory Paediatrics, Adelaide Children's Hospital, Division of the Women's and Children's Hospital and Department of Paediatrics, University of Adelaide, Adelaide, South Australia, Australia

$R$ W Byard

$S$ Beal

A J Bourne

Correspondence to: Women's and Children's Hospital, 72 King William Road, North Adelaide, 5006, South Australia Australia.

Accepted 7 September 1994 Dr Roger W Byard, Department of Histology,

Abstract

Infants and young children may be exposed to a variety of dangerous situations when left sleeping in cots, chairs, or beds. A review of 30 cases of accidental asphyxia occurring in infants and young children who had been left to sleep unattended was undertaken from the necropsy and consultation files of the Adelaide Children's Hospital. Causes of death included hanging from loose restrainers, clothing, or a curtain cord (12 cases), positional asphyxia/wedging from slipping between a mattress and bed/cot sides or wall, or from moving into a position where the face was covered and the upper airway occluded (16 cases), and suffocation from plastic bed covers (two cases). Cases of co-sleeping in bed with an adult and of non-accidental asphyxia were not included in this review. As the pathological findings were on occasion identical to those that are typically found in sudden infant death syndrome, adequate death scene examination was vital in several cases to allow identification of lethal sleeping environments and to enable steps to be taken to minimise the risk of future deaths due to similar

Circumstances of death in 30 cases of accidental childhood asphyxia

\begin{tabular}{|c|c|c|c|c|c|}
\hline $\begin{array}{l}\text { Case } \\
\text { No }\end{array}$ & $\begin{array}{l}\text { Month } \\
\text { year }\end{array}$ & $\begin{array}{l}\text { Age } \\
\text { (months) }\end{array}$ & Sex & Circumstances & $\begin{array}{l}\text { Time } \\
\text { unsupervised }\end{array}$ \\
\hline $\begin{array}{l}1 \\
2 \\
3 \\
4 \\
5 \\
6\end{array}$ & $\begin{array}{r}6 / 66 \\
1 / 70 \\
6 / 70 \\
10 / 74 \\
1 / 76 \\
2 / 76\end{array}$ & $\begin{array}{r}36 \\
18 \\
9 \\
8 \\
17 \\
6\end{array}$ & $\begin{array}{l}\mathbf{M} \\
\mathbf{M} \\
\mathbf{F} \\
\mathbf{F} \\
\mathbf{M} \\
\mathbf{M}\end{array}$ & $\begin{array}{l}\text { Cardigan caught on hook outside cot } \\
\text { Jacket caught on exposed screw on cot } \\
\text { Chin caught on faulty cot railing } \\
\text { Slipped in baby car seat } \\
\text { Jumper caught on cot post } \\
\text { Suspended between foot of adult bed and } \\
\text { mattress }\end{array}$ & $\begin{array}{l}\text { Unknown } \\
\text { Overnight } \\
15 \text { Minutes } \\
\text { Minutes } \\
3 \text { Hours } \\
\text { 3.5 Hours }\end{array}$ \\
\hline $\begin{array}{r}7 \\
8 \\
9 \\
10 \\
11 \\
12 \\
13\end{array}$ & $\begin{array}{r}1 / 78 \\
5 / 78 \\
1 / 81 \\
10 / 81 \\
12 / 81 \\
12 / 82 \\
5 / 83\end{array}$ & $\begin{array}{l}1 \\
8 \\
7 \\
9 \\
8 \cdot 5 \\
35 \\
14\end{array}$ & $\begin{array}{l}\mathbf{F} \\
\mathbf{M} \\
\mathbf{M} \\
\mathbf{M} \\
\mathbf{F} \\
\mathbf{M}\end{array}$ & $\begin{array}{l}\text { Sheet of plastic in pram covered face } \\
\text { Nightdress caught on cot } \\
\text { Hanging from cot } \\
\text { Suspended through bottom of faulty cot } \\
\text { Head wedged between mattress and furniture } \\
\text { Hanging from curtain cord } \\
\text { Suspended by chin between adult bed and } \\
\text { chest of drawers }\end{array}$ & $\begin{array}{l}\text { Unknown } \\
\text { Unknown } \\
\text { Unknown } \\
\text { Hours } \\
\text { Overnight } \\
4 \text { Hours } \\
1 \text { Hour }\end{array}$ \\
\hline $\begin{array}{l}14 \\
15 \\
16 \\
17 \\
18\end{array}$ & $\begin{array}{r}3 / 84 \\
5 / 84 \\
10 / 85 \\
6 / 86 \\
7 / 87\end{array}$ & $\begin{array}{c}15 \\
11 \\
10 \\
8 \\
1 \cdot 5\end{array}$ & $\begin{array}{l}\text { F } \\
\text { M } \\
\text { M } \\
\text { F }\end{array}$ & $\begin{array}{l}\text { Cardigan caught on cot } \\
\text { Cardigan caught on wing nut on cot } \\
\text { Suspended through bottom of faulty cot } \\
\text { Slipped down in pushchair } \\
\text { Face covered by plastic sheet used to cover } \\
\text { mattress }\end{array}$ & $\begin{array}{l}\text { Unknown } \\
45 \text { Minutes } \\
\text { Overnight } \\
\text { Overnight } \\
\text { Unknown }\end{array}$ \\
\hline $\begin{array}{l}19 \\
20 \\
21 \\
22 \\
23\end{array}$ & $\begin{array}{r}3 / 88 \\
8 / 89 \\
11 / 89 \\
11 / 89 \\
3 / 91\end{array}$ & $\begin{array}{l}5 \\
3 \\
4 \\
1 \cdot 5 \\
11 \cdot 5\end{array}$ & $\begin{array}{l}\mathbf{F} \\
\mathbf{M} \\
\mathbf{M} \\
\mathbf{M} \\
\mathbf{M}\end{array}$ & $\begin{array}{l}\text { Head wedged between mattress and bedhead } \\
\text { Face down between pillows and back of couch } \\
\text { Head wedged in cot } \\
\text { Wedged between mother and back of couch } \\
\text { Head wedged between edge of mattress and } \\
\text { mesh wall of cot }\end{array}$ & $\begin{array}{l}\text { Unknown } \\
2 \text { Hours } \\
1 \cdot 5 \text { Hours } \\
3 \text { Hours } \\
\text { Overnight }\end{array}$ \\
\hline $\begin{array}{l}24 \\
25 \\
26\end{array}$ & $\begin{array}{r}11 / 91 \\
1 / 92 \\
9 / 92\end{array}$ & $\begin{array}{l}14 \\
3 \\
2 \cdot 5\end{array}$ & $\begin{array}{l}\mathbf{F} \\
\mathbf{F} \\
\mathbf{M}\end{array}$ & $\begin{array}{l}\text { Wedged between bed and exposed wall cavity } \\
\text { Face down in faulty rocking cradle } \\
\text { Face down in rocking cradle - stabilising peg } \\
\text { out }\end{array}$ & $\begin{array}{l}\text { Overnight } \\
3 \text { Hours } \\
3 \text { Hours }\end{array}$ \\
\hline 27 & $8 / 93$ & 3 & $\mathbf{F}$ & $\begin{array}{l}\text { Slipped down in baby bouncer, hanging from } \\
\text { straps }\end{array}$ & 2 Hours \\
\hline $\begin{array}{l}28 \\
29\end{array}$ & $\begin{array}{l}11 / 93 \\
11 / 93\end{array}$ & $\begin{array}{r}10 \\
6\end{array}$ & $\mathbf{F}$ & $\begin{array}{l}\text { Wedged between adult bed and wall } \\
\text { Head wedged between end of adult bed and } \\
\text { wall }\end{array}$ & $\begin{array}{l}\text { Overnight } \\
\text { Overnight }\end{array}$ \\
\hline 30 & $1 / 94$ & 16 & $\mathbf{M}$ & $\begin{array}{l}\text { Slipped down in child restraint seat in car, } \\
\text { hanging from straps }\end{array}$ & 20 Minutes \\
\hline
\end{tabular}

situations. For example, two cases in which infants asphyxiated in rocking cradles led to the investigation of the cradles and to formulation of specific safety recommendations regarding the angle of tilt. Two infants who died after becoming wedged between the back of a couch and a co-sleeping parent in one case and cushions in the other, would indicate that this also represents a potentially lethal sleeping position. Other dangerous situations involved infant car seat restraints, seats with loose harnesses, cots with movable sides or projecting pieces, thin plastic mattress/pillow coverings, and beds with spaces between the mattress and cot side or wall. Lack of supervision at the time of death was a feature of each case.

(Arch Dis Child 1994; 71: 497-500)

Recent research attention has focused on the role of the prone sleeping position in the aetiology of sudden infant death syndrome (SIDS). ${ }^{1}$ Also of importance due to the preventable nature of the deaths are situations in which the infant sleeping environment is unsafe. After the recent hanging death of a local infant in a car restraint seat a review was undertaken of the range of situations in which an infant left to sleep may be at risk of sudden and unexpected death due to accidental asphyxia.

\section{Methods}

Necropsy records and consultation files at the Adelaide Children's Hospital department of histopathology were examined over the past 28 years (1966-93). Cases of unexpected deaths in infants and young children due to accidental asphyxia caused by unsafe sleeping situations were reviewed.

Deaths were attributed to hanging if there was unequivocal evidence of suspension with ligature marks around the neck, and to chest/airway compression in cases where the body was found wedged between the mattress and cot side or wall. In other cases where the mechanism of death was more complicated involving a combination of hanging, wedging, and airway occlusion, deaths were attributed to positional asphyxia.

As this review is concentrating on structurally unsafe sleeping environments, cases that were excluded include asphyxial deaths due to more generalised unsafe environmental conditions such as carbon monoxide poisoning, deaths due to possible parentally induced 


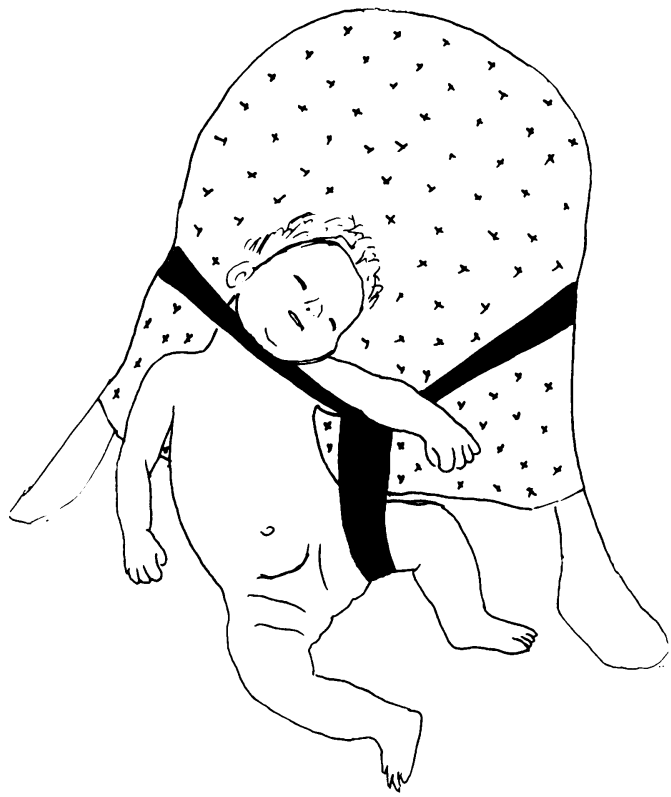

Figure 1 Sketch of a 3 month old girl who was found dead hanging from the loose harness of her baby bouncer; facial petechiae were present.

airway obstruction, deaths due to inhaled foreign bodies, and deaths of infants co-sleeping in bed with adults.

\section{Results}

Thirty cases were identified, the details of which are summarised in the table. Ages ranged from 1 month to 3 years with an average age of approximately 10 months. The male to female ratio was $16: 14$. Causes of death involved hanging (fig 1) from loose restrainers, clothing, or a curtain cord (12 cases), positional asphyxia/wedging (fig 2) from slipping between the mattress and cot sides or wall, or between a sleeping parent/pillow and the back of a couch, or from moving into a position where the face was covered and the upper airway occluded (16 cases), and suffocation from plastic bed covers (two cases). (The pathological features of 12 of these cases have been previously reported. ${ }^{2}$ )

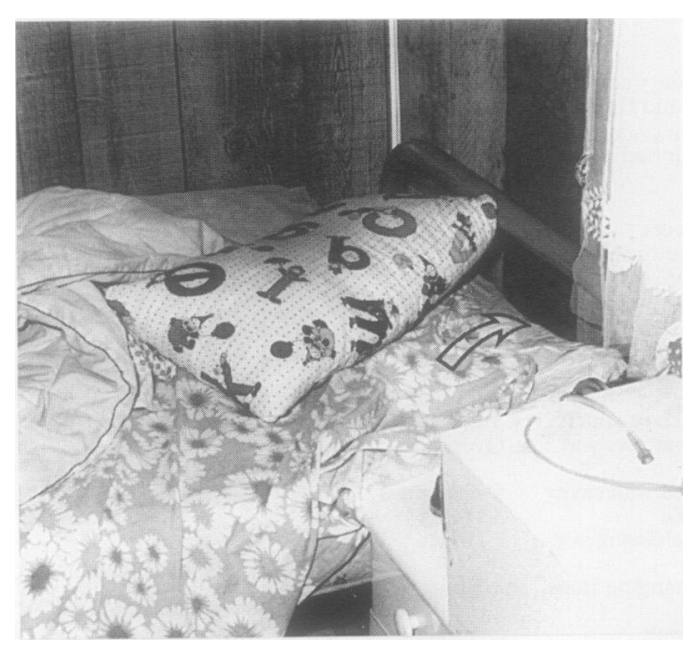

Figure 2 The body of a 14 month old girl was extricated from the space between the head of the bed and the adjacent unlined wall. The arrow indicates the gap through which she crawled.
The diagnoses of positional asphyxial deaths due to compression of the chest and airways by wedging of the body were less clear cut than hanging, often due to a failure to pass on to the examining pathologist pertinent information regarding the position of the body at the death scene. For example, fig 2 illustrates a consultation case where a diagnosis of SIDS had been initially considered until death scene information became available. The case involved a 14 month old girl who was put to sleep in an older sibling's bed (case 24). She was found dead wedged between the bed and the unlined wall joists, having crawled under the bar at the head of the bed. Given that the bed had to be dismantled to release the body, a diagnosis of death due to accidental asphyxia from wedging was considered more appropriate than the original diagnosis of SIDS. Other wedging deaths occurred in situations where the infant's mattress was quite thick and smaller than the cot, thus permitting the infant to slip into the crevice between the mattress and cot sides.

One case of positional asphyxia occurred due to the pliability of the woven mesh side of a cot that allowed an infant's head and upper body to slip into the space at the edge of the mattress (case 23). The elastic recoil of the mesh then forced the infant's head and face into the side of the mattress resulting in suffocation. Infants sleeping in older sibling's or parents' beds are also in danger of slipping between the mattress side and the wall when a gap of sufficient size exists.

Two infants died when they slipped off pillows into the crevice at the back of a couch, formed in one case by an adjacent sleeping parent (case 22), and in the other by outward displacement of the bottom cushions of the couch (case 20). Several cases of fatal positional asphyxia occurred in faulty cots where infants slipped between the side and the base of a cot, or through the bottom of the cot, or became caught in faulty railings (cases 3, 10, and 16).

Although the Adelaide Children's Hospital is the major paediatric treatment centre in South Australia, serving a population which has ranged from 1094984 in 1986 to 1459000 in $1992,{ }^{3}$ the numbers of locally referred paediatric forensic cases and interstate consultation cases contributing to the total number of departmental necropsy cases has varied over the 28 years of the study. While most local paediatric forensic cases would have had a necropsy performed in the department, the variability in referral pattern precludes the drawing of too many formal epidemiological conclusions from the data. The material represents one institution's experience of fatal paediatric sleeping environments, accounting for less than $1 \%$ of the total number of necropsies overall.

\section{Discussion}

Hanging deaths due to ligature suspension in infants are among the most readily diagnosable causes of accidental asphyxial death due to the position of the body at the death scene and to 
the pathological findings elicited at necropsy. In the Adelaide Children's Hospital series a variety of risk factors were identified. For example, several infants had been sleeping in seats with loose restraining harnesses such as car seats, pushchairs (strollers), or baby bouncers (bouncinettes). These infants had slipped out of the restraints which had then caught around their necks resulting in hanging. This situation is illustrated in fig 1 by a 3 month old infant who was found hanging in her baby bouncer, having partially slipped out of the harness after being left unattended. Older children may also be at risk such as the 16 month old boy who was left alone for some time in a car seat restrainer (case 30). Older children who were able to stand in their cots had also asphyxiated from hanging either as a result of putting their heads through a nearby curtain cord in one case or from catching clothing on projections on the sides of their cots. Hazardous sleeping environments were found to be particularly dangerous for infants and younger children, with no children older than 3 years being detected in this series. Lack of supervision at the time of fatal asphyxiation was a feature of all of the cases where a history was available.

The space between the mattress of an adult or older sibling bed and the wall represents a potentially dangerous environment for infants and positional asphyxia associated with wedging in such situations had been reported in other series. ${ }^{4}$ Airway occlusion may also occur in cots with slats that were widely separated or broken allowing trapping of the head. ${ }^{5}$ Although legislation with well defined safety specifications now covers the manufacture of most cot types in Australia, it is almost impossible to apply these rules to secondhand or broken cots. Unfortunately legislation also does not yet cover rocking cradles in which the cot is pivoted from an overhead frame, thus allowing tilting to occur. Deaths of two young infants who were left untended in rocking cradles with marked angles of tilt and faulty locking devices prompted a recent investigation by one of the authors (SB). The infants had asphyxiated when they were unable to extricate their heads from the angle between the side and the floor of the cot. ${ }^{6} \mathrm{~A}$ recommendation of a maximum angle of tilt of $5^{\circ}$ has been made after an examination of infant responses to different angles of tilt under a variety of experimental conditions.

Necropsy findings in cases of asphyxia due to wedging may be quite non-specific and may be identical to those found in cases of SIDS. ${ }^{4}$ Thus without a careful death scene examination and report to the pathologist, there is the possibility that such cases may be misdiagnosed. Occasionally, however, unusual patterns of lividity or bruising around the face or back and side of the head may provide morphological evidence of wedging of the body. For example, linear facial marking with unilateral congestion was demonstrated in a 10 month old girl who slipped between the mattress and the wall while sleeping in an adult bed (case 28).
Unfortunately, necropsy findings in cases of upper airway occlusion are also relatively non-specific. Thus, cases in which an infant has been found with the plastic covering of a mattress or pillow around the face are usually indistinguishable pathologically from SIDS. Attention has also been drawn to the dangers to infants sleeping on waterbeds as an infant may suffocate in the deep hollow caused by the weight of the body and the head on the bed. ${ }^{7}$ Infant deaths on waterbeds were rare in the Adelaide Children's Hospital necropsy files and when such deaths did occur, the beds were not thought to be causally related as they were either rightly filled and not indentable, or else non-asphyxial causes of death were identified. Recent evidence has also demonstrated that rebreathing of carbon dioxide may play a part in the deaths of infants sleeping on polystyrene bags $^{8}$ and possibly on natural fibre mattresses. ${ }^{9}$ The contribution of rebreathing to the lethal event in SIDS and some cases of positional asphyxia awaits further clarification.

The prevention of accidental deaths such as those described in this series is obviously a priority. Continued parental and community education on potential dangers for sleeping infants is needed and pamphlets detailing particular problems could be made available at child care centres and outpatient facilities. Specific dangers to be mentioned would include poorly fitting mattresses with gaps along the sides, plastic bags including filmy plastic mattresses and pillow covers, the use of adult or older sibling beds for infants (including water beds), sleeping on couches, secondhand and broken cots, cots with elastic mesh sides, rocking cradles with excessive angles of tilt and faulty locking devices, cots with projecting hooks or catches, any bed within reach of curtain cords, seats with loose harnesses or restraining belts, and unsupervised car restraint seats, pushchairs, and baby bouncers. While signs warning of the dangers of lack of supervision should be displayed prominently on seats with restraints, these may still be ignored by parents with dire consequences, as occurred in case 30 where a label warning against leaving a child unsupervised in the harness was clearly visible. Legislation should also be enacted to ensure that cots and infant/child seats meet minimum safety standards before sale.

As necropsy markers of asphyxia in infants may be absent or very subtle there exists a potential for the misdiagnosis of SIDS in cases of accidental asphyxia. Although the usefulness and practicality of death scene investigation has been recently questioned, ${ }^{10} 11$ we consider that careful death scene investigation in all cases of sudden infant death is vital so that the causes of accidental death can be accurately determined and potentially dangerous sleeping environments identified. Publicising hazardous sleeping arrangements may make parents and infant minders aware of potentially dangerous situations, and reporting of unsafe cots or beds may result in their modification or withdrawal from sale. 
We would like to thank $\mathrm{Mr}$ Wayne Chivell, coroner, Adelaide, for permission to use fig 1 and Mr Frank Potts, coroner, Hobart, for permission to use fig 2 .

1 Stanley FJ, Byard RW. The association between prone sleeping position and SIDS: an editorial overview. sleeping position and SIDS: an edito

2 Moore L, Byard RW. Pathological findings in hanging and wedging deaths in infants and young children. Am $f$ Forensic Med Pathol 1993; 14: 296-302.

3 Gardner PM. Population. South Australian year book. No 28 1994. South Australia: Australian Bureau of Statistics, Government Printer, 1994: 49-55.

4 Cohle SD. Accidental death. In: Byard RW, Cohle SD, eds. Sudden death in infancy, childhood and adolescence. Cambridge: Cambridge University Press, 1994: 6-46.

5 Variend S, Usher A. Broken cots and infant fatality. Med Sci Law 1984; 24: 111-2.

6 Moore L, Bourne AJ, Beal S, Collett M, Byard RW.
Unexpected infant death in association with suspended rocking cradles. Am $\mathcal{f}$ Forensic Med Pathol (in press).

7 Gilbert-Barness E, Hegstrand L, Chandra S, et al. Hazards of mattresses, beds and bedding in deaths of infants. $A m \mathcal{F}$ of mattresses, beds and bedding in deaths of infants. Am
Forensic Med Pathol 1991; 12: 27-32.

$8 \mathrm{Kemp}$ JS, Thach BT. Sudden death in infant sleeping on polystyrene-filled cushions. $N$ Engl f Med 1991; 324: 1858-64.

9 Ponsonby AL, Dwyer T, Gibbons LE, Cochrane JA, Wang Y-G. Factors potentiating the risk of sudden infant death syndrome associated with the prone position. $N$ Engl $\mathcal{F}$ Med 1993; 329: 377-82.

10 Sankaran K. Sudden infant death syndrome: an interactive hypothesis and a personal perspective for prevention. Annals of the Royal College of Physicians and Surgeons of Canada 1993; 26: 277-80.

11 Guntheroth WG, Spiers PS, Naeye RL. Redefinition of the sudden infant death syndrome: the disadvantages. Pediatr Pathol 1994; 14: 127-32. 